American Journal of Environmental Sciences 6 (4): 357-364, 2010

ISSN 1553-345X

(C) 2010 Science Publications

\title{
Bioengineering Assessment on Sloppy Ground
}

\author{
Mu'azu Mohammed Abdullahi, Nazri Bn Ali and Kamarudin Bn Haj Ahmed \\ Department of Geotechnics and Transportation, Faculty of Civil Engineering, \\ University Technology Malaysia, 81310 UTM Skudai, Johor Bahru, Johor, Malaysia
}

\begin{abstract}
Problem statement: Soft engineering solution of sloppy surface utilizes mechanical and hydrological effects of vegetation. The hydrological effects driven by transpiration, induces an increase in matric suction and consequently tension also increase along with the decrease of moisture. Therefore once the horizontal stress of the soil exceeds the limit of tensile strain of the soil cracks occurs. Approach: The negative pore-water pressures estimated through an unsaturated water-uptake analysis. The results of the root water-uptake analysis are then used as an input for the prediction of displacements in a stress-deformation analysis in an uncoupled formulation. The formulation of the governing partial differential equations for both water-uptake and stress-deformation is based on the general theory of unsaturated soils. The ground displacement presented here only considers hydrological effects which are related to soil moisture variations driven by transpiration. Results: The ground displacement profiles as a result of matric suction changes at key times and at key locations have been presented. The matric suction changes induced settlements are estimated. The magnitude of the ground displacement depends on the relative position of the tree on the slope. The ground displacement depends, to some extent, on the precise position of the tree. Conclusion: These showed that excessive increase matric suction and tension due to decrease of moisture can lead settlement. Moisture reduction reaching a critical state causes cracks to be established, of course has negative consequences on sloppy ground.
\end{abstract}

Key words: Unsaturated soils, metric suction, water-uptake, simulation, deformation

\section{INTRODUCTION}

This study aims to examine the influence of such variations within the context of embankment slope. The application of the water-uptake model, with uncoupled stress-deformation analysis were used to provide a preliminary assessment of ground settlement due to ground water abstraction, resulting from suction changes on the stability of unsaturated soil slopes. This research only considers hydrological effects only. The study presented employs typical slope geometry. A range of initial conditions and tree locations have been considered. Most researchers considered the mechanical and hydrological effects of vegetation in the beneficial context, neglecting that in unsaturated soils, matric suction and tension increase along with the decrease of moisture, therefore tensile strength clearly depends on suction. Moisture reduction reaching a critical state, then cracks would be established on the ground surface, releasing of the tension energy. The depth and formation of more cracks is directly proportional to further moisture depletion. If this occurs on a sloppy surface, it will lead to increase in penetrability and even trigger sliding during heavy rains. This presence of cracks accelerates evaporation process and preferential flow.

Cracks may occur due to settlement once the horizontal stress caused by desiccation of the soil exceeds the limit of tensile strain of the soil. The adverse effects include decreased strength of the cracked soils and increased flow through the soils. Desiccation cracks are important issue in geotechnical engineering. Globally, desiccation cracks affect the overall stability and bearing capacity of cracked soil masses. Cracks formed as a consequence of desiccation can greatly affect the stability of slopes.

Net horizontal stresses in unsaturated soils decrease with increasing metric suctions (Fredlund and Rihardjo, 1993). He added that horizontal stresses can become zero or negative due to increasing matric suctions. Since soils can only sustain small amounts of tensile stress, cracks develop when the net horizontal stresses become more negative than the tensile strength of the soil. High confining pressures can reduce

Corresponding Author: Mu'azu Mohammed Abdullahi, Department of Geotechnics and Transportation,

Faculty of Civil Engineering, University Technology Malaysia, 81310 UTM Skudai, Johor Bahru, Johor, Malaysia Tel: +60178223310 
development and progression of cracks by increasing the net horizontal stresses.

Morris et al. (1992) state that conditions for crack propagation are most favorable at the ground surface where self-weight stresses are zero and matric suctions are maximum. The depth of cracks is constrained by the increasing stresses due to soil self-weight and their surfacial length is limited by intersection with other cracks.

Some researchers (Thorne, 1990; Simon and Darby, 1999; Simon et al., 2000) claim that vegetation is widely believed to increase the stability of a slope. Simon and Collison (2002) suggested that the impact of vegetation can be generally categorized as either mechanical or hydrological. Mechanical effects arise from the tensile strength of roots and the weight of vegetation. Hydrological effects are related to the soil moisture variations that are predominantly driven by transpiration. Hydrological effects are almost entirely subsurface processes when canopy interception is negligible. Seasonal variation (winter/early spring when the deciduous trees are dormant) and the intensity of rainfall influence overall behavior. A key finding of Simon and Collison (2002) study was that the hydrological effects were found to be as important as mechanical effects and in certain cases, providing a more significant increase in the stability of a slope. Design, repair, maintenance and operation of railway and road earthworks are particular areas where this is an important issue. Previous experience in Malaysia illustrated that removal of vegetation can be the main cause of the failure of a slope (Rees and Ali, 2006). In this tragedy, one block of a 14 storey building of the Highland Towers Condominium suddenly toppled over and collapsed and killed 48 people. Investigation of the substructure and the surroundings revealed that clearing of trees on the adjacent slope led to the water level in soil to rise, thus causing the instability of slope.

Ridley et al. (2004) discussed the relationship between climate, in the form of soil moisture deficit, the presence of trees and pore-water pressures in embankments. The study showed that most embankment failures in London were due to an increase in soil moisture content. An increase in soil moisture content occurred when there was no water uptake from trees during winter time (no transpiration for deciduous trees during this period). These findings further clarify of the importance of tree-water uptake in increasing the stability of slopes. Further evidence of the importance of soil suction changes on shear strength is also available in the literature.

The mechanical parameters of the soil were included in the water flow analysis and have been simulated. A seasonal water variation as a result of root water-uptake was measured by Biddle (1998). A simple concept of sink term for uptake developed by Rees and Ali (2006) is partial coupled to estimate the deformation as a result of vegetative induced metric suction changes in this study, incorporating the elapse time with flux boundary condition in the analysis.

Theoretical formulation: The continuity principles applied to the flow in two directions in a referential element yields the two-dimensional axi-symmetric domain:

$$
-\frac{\partial \theta}{\partial t}=\frac{\partial v_{x}}{\partial x}+\frac{\partial v_{z}}{\partial z}
$$

Where:

$\mathrm{V}_{\mathrm{T}}=$ The total volume of soil

$\mathrm{V}_{\mathrm{w}}=$ The volume of water in the soil pores

$\mathrm{V}_{\mathrm{x}}=$ The velocity of water flow in the $\mathrm{x}$ direction

$\mathrm{V}_{\mathrm{z}}=$ The velocity of water flow in the $\mathrm{z}$ direction

By employing Darcy's Law expression for flow in an unsaturated soils. The total potential for the moisture flow taken as the sum of the pressure or capillary potential and the gravitational potential given in Eq. 1.

The traditional slope stability problem is formulated as a two-Dimensional (2-D) plane problem. In order to obtain some compatibility between the two formats, the moisture flow simulation undertaken here is also conducted in $2 \mathrm{D}$ plane geometry. At the same time combining the standard two-dimensional Richard's equation provides the 2D plane form of the water uptake model:

$$
\begin{aligned}
C(\psi) \frac{\partial \psi}{\partial t}= & \frac{\partial}{\partial x}\left(k_{w}^{x} \frac{\partial}{\partial x}\left(\frac{u_{w}}{\rho_{w} g}+Z\right)\right)+\frac{\partial}{\partial z}\left(K_{w}^{z} \frac{u_{w}}{\rho_{w} g}+Z\right) \\
& +\frac{\partial}{\partial z}\left(k_{w}^{z} \frac{\partial}{\partial z}\left(\frac{u_{w}}{\rho_{w} g}+Z\right)\right)-S(x, z)
\end{aligned}
$$

Where:

$\mathrm{K}=$ The unsaturated hydraulic conductivity

$\mathrm{t}=$ The time, $\mathrm{x}$

$\mathrm{z}=$ The Cartesian coordinate

$\theta=$ The volumetric moisture content

$\Psi=$ The capillary potential

$\mathrm{s}(\mathrm{x}, \mathrm{z})=$ The root water extraction function

$\mathrm{x}=$ The radial coordinate

A solution of Eq. 2 was obtained via application of the numerical techniques described in Eq. 4.

The root water-uptake extraction function is the sink term $S(\psi, z, x)$ in the Eq. 2 is given by the Eq. 3 for water-uptake for two-dimensional form (Rees and Ali, 
2006). To deal with 2-D plane problem, modification of the flow equation has been made. The sink term must now be based on the $\mathrm{x}$ co-ordinate in place of radial coordinate, $r$ used for the axi-symmetric form. Therefore:

$\mathrm{S}(\psi, \mathrm{x}, \mathrm{z})=\frac{4 \mathrm{~T}}{\mathrm{z}_{\mathrm{r}} \mathrm{x}_{\mathrm{r}}} \alpha(\psi)\left(1-\frac{\mathrm{z}}{\mathrm{z}_{\mathrm{r}}}\right)\left(1-\frac{\mathrm{x}}{\mathrm{x}_{\mathrm{r}}}\right)$

Where:

$\mathrm{x}_{\mathrm{r}}=$ The maximum rooting depth in the $\mathrm{x}$-direction

$\mathrm{z}_{\mathrm{r}}=$ The maximum rooting depth

$\mathrm{x}=$ The $\mathrm{x}$-distance from the origin of the plant trunk

$\mathrm{z}=$ The depth in the soil profile

The numerical solution of Eq. 3 via the finite element spatial discretization procedure and a finitedifference time-stepping scheme particular adopting a Galerkin weighted residual approach which will yield the disctretized matrix form with added deformation component by Rees and Ali (2006):

$$
\mathrm{K} \psi_{\mathrm{s}}+\mathrm{C} \frac{\psi_{\mathrm{s}}}{\partial \mathrm{t}}+\mathrm{J}+\mathrm{S}=0
$$

The parabolic shape functions and eight-node isoperimetric elements are employed (Zienkiewicz and Taylor, 1989). The time-dependent nature of Eq. 4 is dealt with via a mid-interval backward difference technique, in Eq. 5, yielding:

$$
\mathrm{K}^{\mathrm{n}+1 / 2} \psi^{\mathrm{n}+1}+\mathrm{C}^{\mathrm{n}+1 / 2}\left[\frac{\psi^{\mathrm{n}+1}-\psi^{\mathrm{n}}}{\Delta \mathrm{t}}\right]+\mathrm{J}^{\mathrm{n}+1 / 2}+\mathrm{S}^{\mathrm{n}+1 / 2}=0
$$

The capillary potential $(\psi)$ was estimated from Eq. 2, which was used as an input for the stressdeformation analysis.

The elasticity parameters are functions of the stress state of the soil, net normal stress and the metric suction. The elasticity parameters could be estimated using equation from Fredlund and Hung (2001) they were coded into FORTRAN code.

While the soil is normally consolidated clay with a consolidation behavior that can be described by:

$$
\text { de }=C_{c} \ln \left(\frac{\sigma_{v}+\Delta \sigma_{v}-u_{w f}}{\left(\sigma_{v}-u_{a}\right)+\left(u_{a}-u_{w}\right)_{e}}\right)
$$

Where:

$$
\begin{array}{ll}
\text { de } & =\text { The change of void ratio in the element } \\
\mathrm{C}_{\mathrm{c}} & =\text { The compression index, is the } \\
& \text { swelling/shrinkage deformation } \\
\mathrm{Cs} & =\text { The swelling index } \\
\sigma_{\mathrm{v}} & =\text { The vertical total stress } \\
\Delta \sigma_{\mathrm{v}} & =\text { The change in the total vertical stresses }
\end{array}
$$

$\mathrm{u}_{\mathrm{wf}} \quad=$ The final pore water pressure

$\left(\mathrm{u}_{\mathrm{a}}-\mathrm{u}_{\mathrm{w}}\right)_{\mathrm{e}}=$ The metric suction equivalent (Fredlund and Rihardjo, 1993)

\section{MATERIALS AND METHODS}

The simulation employs the slope geometry from Fig. 1, which shows the domain and location of the tree. The problem considered is a typical drying period and the moisture migration caused by a single tree. A larger domain size is adopted in order to include the slope geometry. The mesh consists of seven hundred, eightnode isoperimetric elements with 2231 nodes. The mesh was configured to offer some refinement within the root zone area since this is the region where the most significant moisture content variations were expected to occur. Numerical tests were conducted to ensure that for this domain size, the outer boundaries do not significantly influence the simulated results within the region of interest. The simulated period covered a spring/summer soil-drying phase of 9 months. The simulation employs a time-step size of $21600 \mathrm{sec}$ which was held constant for the entire period considered. Again, a check has been made to ensure that the solution is time-step converged. The root zone is assumed to extend to a depth of $2 \mathrm{~m}$ and a radial distance of $5 \mathrm{~m}$ both left and right of the centre line of the tree. The root zone therefore extends beneath the toe of the embankment slope. Although the application of the sink term in the water uptake model applies only within the elliptical root zone, moisture is of course free to migrate towards the tree from regions outside of this zone. Therefore some drying of the embankment can be expected from this scenario.

In effect the transpiration rate is therefore distributed through the root zone via use of the sink term. No flux boundary is therefore specified at the soil surface. The lower boundary of the domain and the farfield vertical boundary remained unconstrained (natural) throughout the simulation. The boundary condition for the stress-deformation analysis in involved having the soil free to move in the vertical direction and fixed in horizontal direction at the left and right sides of the domain and the lower boundary would be fixed in both directions. A mature Lime tree of $15 \mathrm{~m}$ height on boulder clay was considered for this analysis.

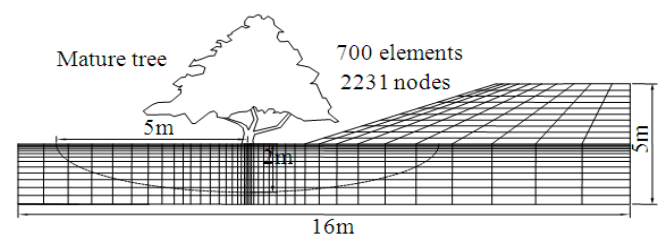

Fig. 1: Finite element mesh $\left(16 \times 5 \mathrm{~m}^{2}\right)$ 
However several modifications in the FORTRAN code have been made to ensure that the water uptake model functions correctly when the tree is positioned anywhere along the slope surface. The soil parameters are shown in Table 1 which is typical values for Boulder clay.

The required soil moisture retention characteristics and unsaturated hydraulic conductivity would be simulated from the closed form equation developed by Van Genuchten (1980) thus:

$$
\begin{aligned}
& \theta(\psi)=\theta_{\mathrm{r}}+\frac{\left(\theta_{\mathrm{s}}-\theta_{\mathrm{r}}\right) \psi \geq 0}{\left[1+|\alpha \psi|^{\mathrm{n}}\right]^{\mathrm{m}} \psi<0} \\
& \mathrm{~K}=\mathrm{Ks} \frac{\left[\left(1+|\alpha \psi|^{\mathrm{n}}\right)^{\mathrm{m}}-|\alpha \psi|^{\mathrm{n}-1}\right]^{2}}{\left(1+|\alpha \psi|^{\mathrm{n}}\right)^{\mathrm{m}(1+2)}}
\end{aligned}
$$

Where:

$$
\begin{aligned}
\theta_{\mathrm{s}} & =\text { The Saturated water content } \\
\theta_{\mathrm{r}} & =\text { The residual water content } \\
\Psi & =\text { The suction head }(\mathrm{cm}) \\
\mathrm{n}, \mathrm{m}, \alpha= & \text { The empirical shape fitting parameters } \\
& \text { estimated by fitting Eq. } 7 \text { and } 8 \text { to the } \\
& \text { experimental data }
\end{aligned}
$$

$\mathrm{K}$ and $\mathrm{K}_{\mathrm{s}}=$ The unsaturated hydraulic conductivity and saturated hydraulic conductivity respectively while 1 is a soil specific parameter generally assumed to be 0.5

Model verification: The numerical results seem to agree with Fredlund and Hung (2001) analysis of Ali and Muazu (2010). The slight disparity between the results is two entirely different unsaturated soil models are used in his study. These are the stress state variable for unsaturated soil with Bishop's effective stress theory for the unsaturated coded using FORTRAN and Fredlund and Hung (2001) strictly stress state variable for unsaturated soils. The two different theories influence the volume of change of an unsaturated soil differently.

Table 1: Parameters used in the analysis

\begin{tabular}{llll}
\hline Parameters & Values & Reference & Remarks \\
\hline $\mathrm{k}_{\mathrm{s}}$ & $10^{-6} \mathrm{~m} \mathrm{sec}^{-1}$ & Biddle (1998) & Typical for Boulder clay \\
$\mathrm{T}_{\mathrm{p}}$ & $5 \mathrm{~mm} \mathrm{day}^{-1}$ & Biddle $(1998)$ & For a mature tree \\
$\Psi_{\mathrm{d}}$ & $1500 \mathrm{kPa}^{-3}$ & Feddes et al. $(1976)$ & $\left(1000 \leq \psi_{\mathrm{w}} \leq 2000\right) \mathrm{kPa}$ \\
$\gamma$ & $21 \mathrm{kN} \mathrm{m}^{-3}$ & Indraratna et al. $(2006)$ & Typical values for Boulder clay \\
$\mathrm{e}_{0}$ & 0.60 & Powrie et al. $(1992)$ & Typical values for Boulder clay \\
$\mathrm{C}_{\mathrm{c}}$ & 0.13 & Indraratna et al. $(2006)$ & Typical values for Boulder clay \\
$\mu$ & 0.30 & Indraratna et al. $(2006)$ & Typical values for clay soils \\
$\theta_{\mathrm{r}}$ & 0.1 & Rees and Ali $(2006)$ & Typical values for Boulder clay \\
$\theta_{\mathrm{s}}$ & 0.4 & Rees and Ali $(2006)$ & Typical values for Boulder clay \\
$\alpha$ & 0.0560 & Rees and Ali $(2006)$ & Typical values for Boulder clay \\
$\mathrm{m}$ & 0.29 & Rees and Ali (2006) & Typical values for Boulder clay \\
$\mathrm{n}$ & 1.4 & Rees and Ali (2006) & Typical values for Boulder clay \\
1 & 0.5 & Rees and Ali (2006) & Typical values for Boulder clay \\
\hline
\end{tabular}

This verification exercise confirms that if the relevant parameters are known, then the current finite element model can predict the metric suction generated and the ground deformation caused by vegetative induced moisture movement. The water uptakes are validated with Biddle (1998) and Rees and Ali (2006).

\section{RESULTS}

Contours of ground displacement generated at the end of the simulation (at 270 days) for tree near the toe of the slope is shown in Fig. 2, while Fig. 3, variation of ground settlement with depth at $6.0 \mathrm{~m}$ from origin.

Figure 4-6 shows the predicted ground displacement profiles for 30,90, 180 and 270 days of the domain as shown in Fig. 2.

Figure 8-11 shows the predicted ground displacement for tree at centre of the slope as shown in Fig. 7 for 30, 90, 180 and 270 days.

For tree at centre of the slope as shown in Fig. 7, the simulated contours of metric suction now generated at the end of the simulation at 270 days for a tree located at the mid-height of the slope is shown in Fig. 7.

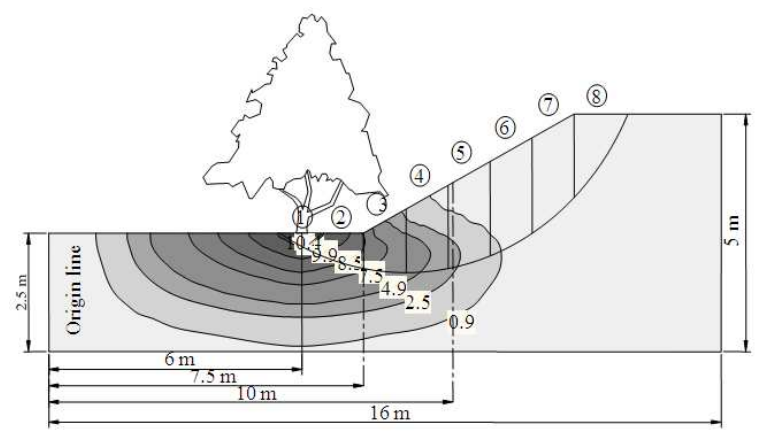

Fig. 2: Ground displacement $(\mathrm{cm})$ contours at 270 days tree located near the toe of slope

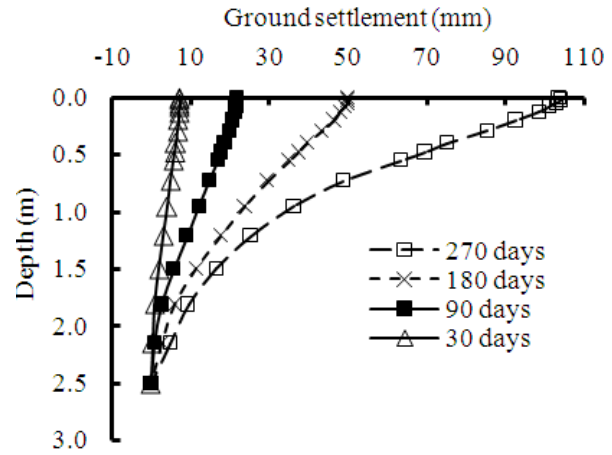

Fig. 3: Variation of ground settlement with depth at 6.0 $\mathrm{m}$ with tree near the toe of slope for various elapse times 


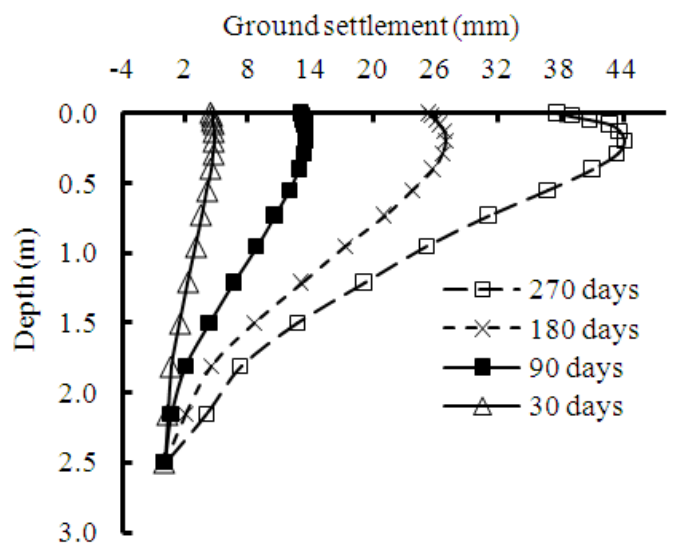

Fig. 4: Variation of ground settlement with depth at 7.5 $\mathrm{m}$ with tree near the toe of slope for various elapse times

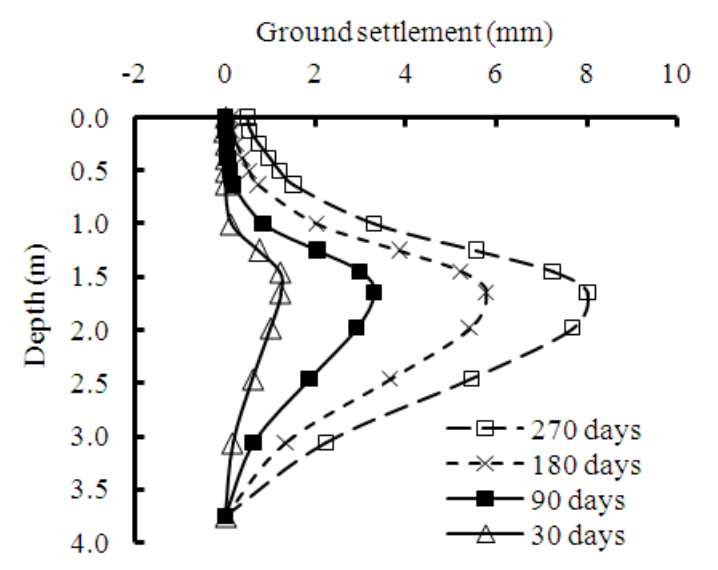

Fig. 5: Variation of ground settlement with depth at $10.0 \mathrm{~m}$ with tree near the toe of slope for various elapse times

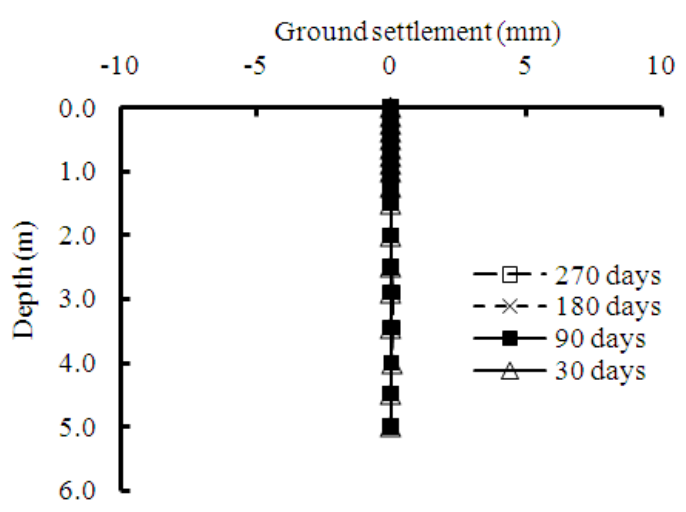

Fig. 6: Variation of ground settlement with depth at $12.5 \mathrm{~m}$ with tree near the toe of slope for various elapse times

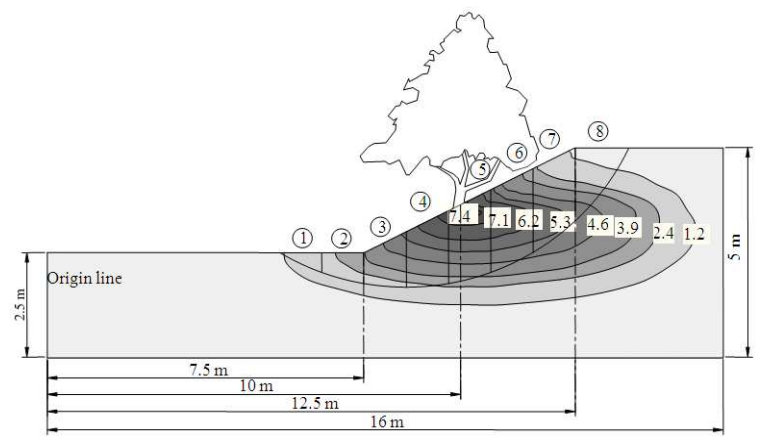

Fig. 7: Ground displacement $(\mathrm{cm})$ contours at 270 days tree at centre of slope

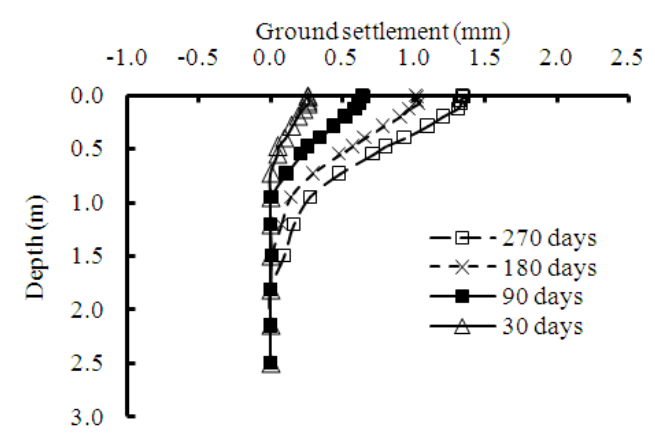

Fig. 8: Variation of ground settlement with depth at $6.0 \mathrm{~m}$ with tree at the centre of slope for various elapse times

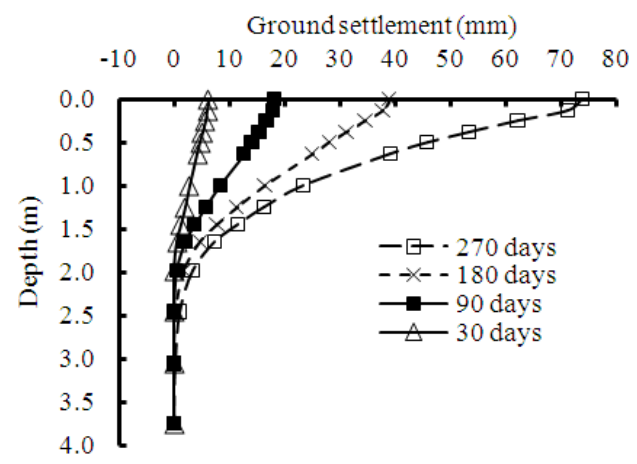

Fig. 9: Variation of ground settlement with depth at $10.0 \mathrm{~m}$ with tree at the centre of slope for various elapse times

Tree at the Top of Slope as shown in Fig. 12 shows the simulated contours of metric suction generated at the end of the simulation at 270 days for a tree at the top of slope. Figure 13-16 shows the predicted ground displacement profiles at a distance of $6.0,7.5$ and $10.0 \mathrm{~m}$ from the origin at times of 30, 90, 180 and 270 days respectively. 


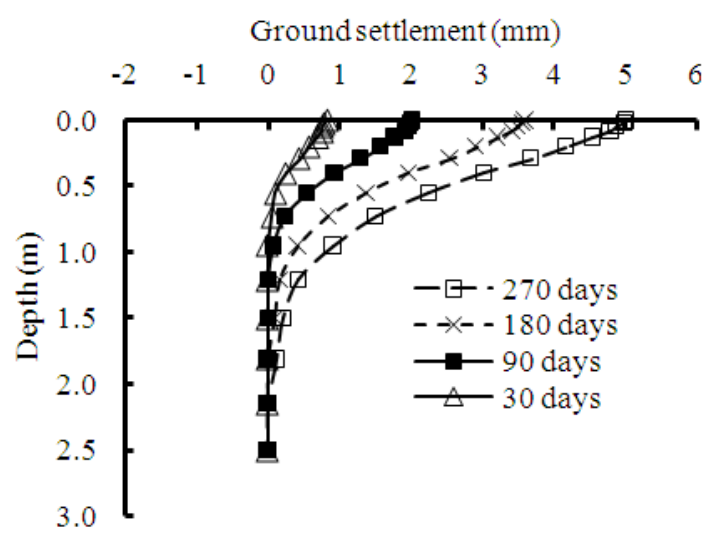

Fig. 10: Variation of ground settlement with depth at $7.5 \mathrm{~m}$ with tree at the centre of slope for various elapse times

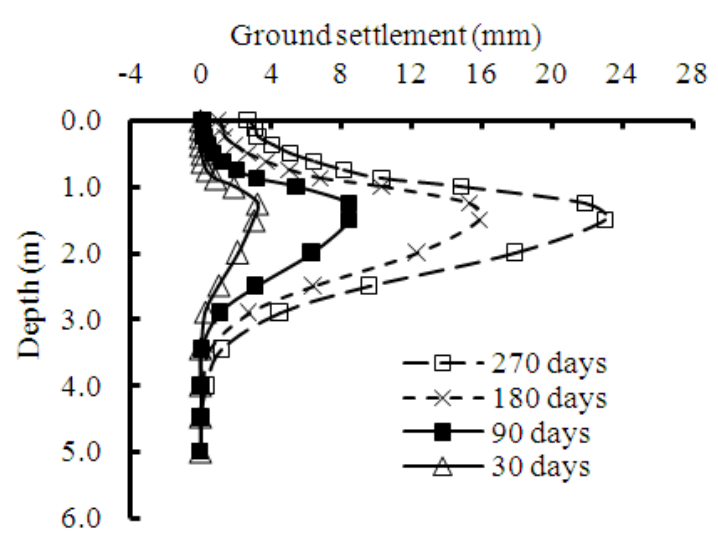

Fig. 11: Variation of ground settlement with depth at $12.5 \mathrm{~m}$ with tree at the centre of slope for various elapse times

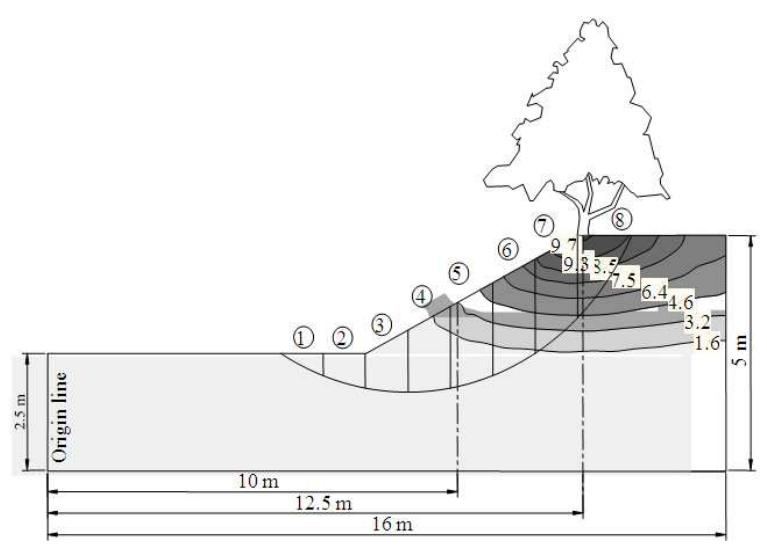

Fig. 12: Ground displacement $(\mathrm{cm})$ contours at 270 days Tree at the top of slope

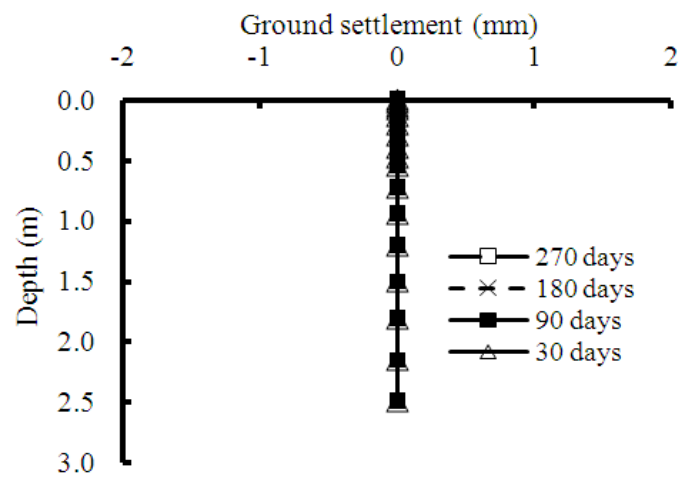

Fig. 13: Variation of ground settlement with depth at $6.0 \mathrm{~m}$ with tree at the top of the slope for various elapse times

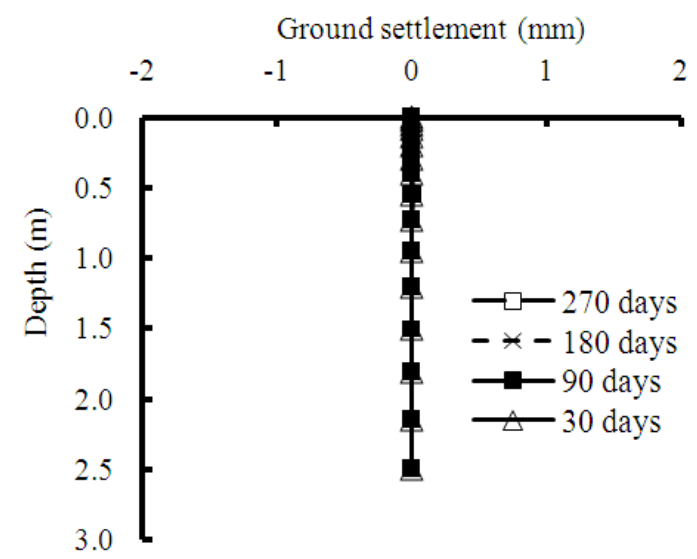

Fig. 14: Variation of ground settlement with depth at $7.5 \mathrm{~m}$ with tree at the top of the slope for various elapse times

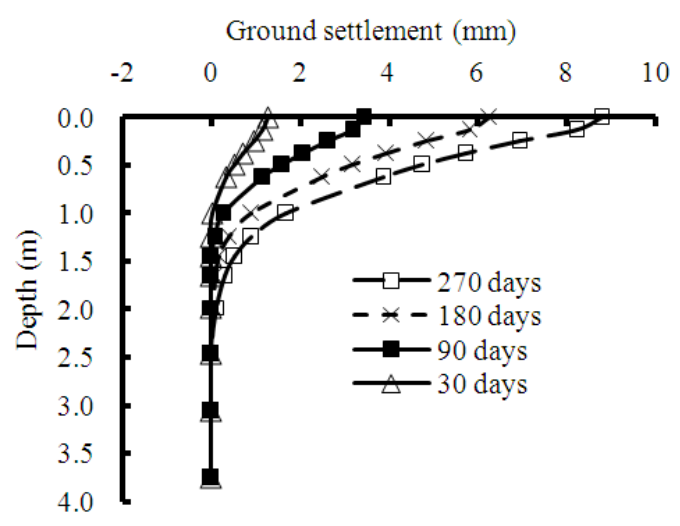

Fig. 15: Variation of ground settlement with depth at $10.0 \mathrm{~m}$ with tree at the top of the slope for various elapse times 
Am. J. Environ. Sci., 6 (4): 357-364, 2010

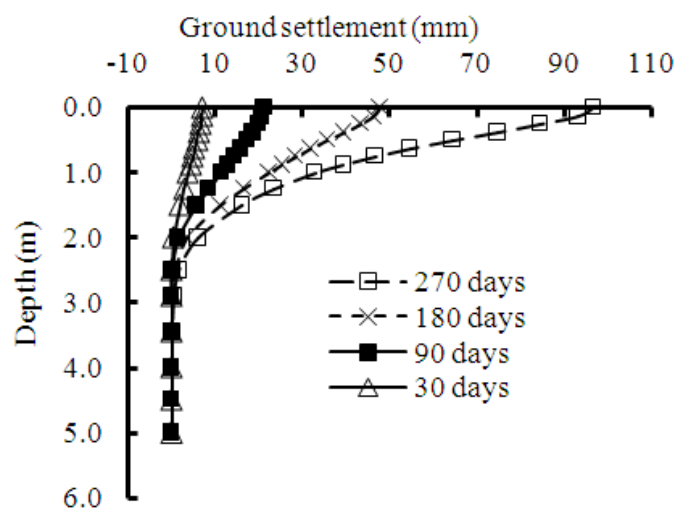

Fig. 16: Variation of ground settlement with depth at $12.5 \mathrm{~m}$ with tree at the top of the slope for various elapse times

\section{DISCUSSION}

Tree near the toe of the slope as shown in Fig. 2 presents the simulated contours of ground displacement generated at the end of the simulation (at 270 days). Figure 12 shows that clear matric suction variations due ground water abstraction resulting in ground displacement within the slope has taken place.

Figure 3 shows the predicted ground displacement profiles at a distance of $6.0 \mathrm{~m}$ from the origin line located at the left hand edge of the domain as shown in Fig. 2 at times of 30, 90, 180 and 270 days. These results are produced for the soil profile directly beneath the centerline of the tree. It is clear that the majority of the moisture extraction has occurred near the surface with the ground displacement of $103.55 \mathrm{~mm}$ at the surface. There is ground displacement profile of zero millimeters at approximately $2.5 \mathrm{~m}$ below the ground surface. The maximum ground displacement has occurred near the surface.

Figure 4 and 5 shows that a very similar set of results were obtained at 7.5 and $10.0 \mathrm{~m}$ from origin line respectively. It should be noted that the change in profiles show relatively little ground displacement compared those at a distance of $6.0 \mathrm{~m}$. At a distance of $10.0 \mathrm{~m}$, Fig. 5 shows that the maximum ground displacement occurred at depth of approximately $1.65 \mathrm{~m}$ from the slope surface and the ground displacement is approximately $8 \mathrm{~mm}$ that point. This ground displacement can be expected since this depth is roughly at the same level as the point at which the tree meets the soils surface at a distance $6.0 \mathrm{~m}$. This level is where the main source of water extraction takes place.

For tree at centre of the slope as shown in Fig. 7, the simulated contours of metric suction now generated at the end of the simulation at 270 days for a tree located at the mid-height of the slope is shown in Fig. 7.
Figure 8 shows the predicted ground displacement at a distance of $6.0 \mathrm{~m}$ from the origin at times of 30,90, 180 and 270 days. The maximum ground displacement occurred near the surface with ground displacement of $1.3 \mathrm{~cm}$ at surface due to the so much lateral distance away from position of the tree.

Figure 9 shows the predicted moisture content profiles at a distance of $10.0 \mathrm{~m}$ from the origin located at left line of the domain as shown in Fig. 7 at times of $30,90,180$ and 270 days. It is clear that the majority of ground displacement has occurred near the slope surface, the profile is roughly linear and there is ground displacement at approximately $3.0 \mathrm{~m}$ below the slope surface.

Figure 10 and 11 show that a very similar set of results was obtained remote from the tree at 7.5 and $12.5 \mathrm{~m}$ from the origin respectively. It should be noted that the ground displacement shown here is small compared to that near the centre of tree. Figure 11, shows the maximum ground displacement at $12.5 \mathrm{~m}$ from the origin occurred at depth $1.5 \mathrm{~m}$ below the slope surface. Again, this ground displacement profile pattern can be explained due to the fact that the depth of $1.5 \mathrm{~m}$ from soil surface is approximately at the same level as the tree. Figure 10 shows less ground displacement occurred at a distance of $7.5 \mathrm{~m}$.

Tree at the top of slope as shown in Fig. 12 shows the simulated contours of metric suction generated at the end of the simulation at 270 days for a tree at the top of slope. Figure 13-15 shows the predicted ground displacement profiles at a distance of $6.0,7.5$ and $10.0 \mathrm{~m}$ from the origin at times of 30, 90, 180 and 270 days respectively.

Figure 16 shows the predicted moisture content profiles at a distance of $12.5 \mathrm{~m}$ from the origin at times of 30,90, 180 and 270 days. Majority of the ground displacement occurred near the slope surface with value of $96.72 \mathrm{~mm}$ at slope surface. The ground displacement profile decreases to $1.7 \mathrm{~mm}$ at approximately $2.9 \mathrm{~m}$ below the slope surface.

\section{CONCLUSION}

The application of a numerical model for the simulation of moisture migration patterns due to tree water uptake as well as accompanying ground movement in a typical soil slope has been presented. The approach was utilized to provide a preliminary assessment of the significance of suction changes on the stability of unsaturated soil slopes. For typical slope geometry, a range of initial conditions and tree locations have been considered. Three locations of a tree on the slope have been considered: at tree located 
near at the toe of the slope, a tree located at the centre of the slope and a tree located and at the top of slope.

The ground displacement profiles as a result of matric suction changes at key times and at key locations have been presented. The ground displacement depends, to some extent, on the precise position of the tree. The ground displacement presented here only considers hydrological effects which are related to soil moisture variations driven by transpiration. Therefore tree location on slope is critical if an informed decision is to be taking in soft engineering stabilization of unsaturated slopes as shown in the graphs.

Excessive matric suction is accompany by increase tension, reaching critical and horizontal stress exceeding tensile strength of the soil, cracks occurs, with a detrimental consequences to the stability of a slope.

\section{REFERENCES}

Ali, N.B. and M.M. Abdullahi, 2010. Simulation of vegetative induced deformation in an unsaturated soil. Am. J. Environ. Sci., 6: 101-107. http://www.scipub.org/fulltext/ajes/ajes61101-107.pdf

Biddle, G., 1998. Tree Root Damage to Buildings: Pattern of Soil Drying in Proximity to Trees on Clay Soils. 1st Edn., Willowmead Publishing, Wantage, ISBN: 095330860X, pp: 675.

Feddes, R.A., P. Kowalik, K. Kolinska-Malinka and H. Zaradny, 1976. Simulation of field water uptake by plants using a soil water dependent root extraction root extraction function. J. Hydrol., 31: 13-26. DOI: 10.1016/0022-1694(76)90017-2

Fredlund, D.G. and H. Rihardjo, 1993. Soil Mechanics for Unsaturated Soil. 1st Edn., Wiley-Interscience, New York, ISBN: 047185008X, pp: 544.

Fredlund, D.G. and V.Q. Hung, 2001. Predictive of volume change in an expensive soil as a result of vegetation and environmental changes. Proceeding of the ASCE Conference on Expansive Clay Soils and Vegetative Influence on Shallow Foundations, Oct. 10-13, Geotechnical Special Publication, Houston, Texas, Reston, pp: 24-43.

Indraratna, B., B. Fatahi and H. Khabbaz, 2006. Numerical analysis of matric suction effects of the tree roots. Geotech. Eng., 159: 77-90. http://works.bepress.com/bindraratna/73/

Morris, P.H., J. Graham and D.J. Williams, 1992. Cracking in drying soils. Can. Geotech. J., 29: 263-277. DOI: $10.1139 / \mathrm{t} 92-030$
Powrie, W., J.N. Davies and A.M. Britto, 1992. A cantilever retaining wall supported by a berm during the temporary work activities. Proceeding of the ICE Conference on Retaining Structures, Robinson College, (RSRC'92), Thomas Telford Service Ltd., Cambridge, London, pp: 418-428. http://www.mycrisp.com/publications/A\%20CAN TILEVER\%20RETAINING\%20WALL\%20SUPP ORTED\%20BY\%20A\%20BERM\%20DURING\% 20TEMPORARY\%20WORKS\%20ACTIVITIES.pdf

Rees, S.W. and N. Ali, 2006. Seasonal water uptake near trees: A numerical and experimental study. Geomech. Geoeng., 1: 129-138. DOI: 10.1080/17486020600823855

Ridley, A., B. McGinnity and P. Vaughan, 2004. Role of pore water pressures in embankment stability. Proc. Inst. Civil Eng.-Geotech. Eng., 157: 193-198. http://cat.inist.fr/?aModele $=$ afficheN\&cpsidt $=1628$ 3232

Simon, A. and A.J.C. Collison, 2002. Quantifying the mechanical and hydrologic effects of riparian vegetation on streambank stability. Earth Surface Process. Landforms, 27: 527-546. DOI: 10.1002/esp. 325

Simon, A. and S.E. Darby, 1999. The Nature and Significance of Incised River Channels. In: Incised River Channels: Processes, Forms, Engineering and Management, Darby S.E. and A. Simon (Eds.). John Wiley and Sons, Chichester, England, ISBN: 0471984469, pp: 3-18.

Simon, A., A. Curini, S.E. Darby and E.J. Langendoen, 2000. Bank and near-bank processes in an incised channel. Geomorphology, 35: 193-217. DOI: 10.1016/S0169-555x(00)00036-2

Thorne, C.R., 1990. Effects of Vegetation on Riverbank Erosion and Stability. In: Vegetation and Erosion: Processes and Environments, Thornes, J.B. (Ed.). John Wiley and Sons, Chichester, UK., ISBN: 10: 0471926302, pp: 125-143.

Van Genuchten, M.T., 1980. A closed-form equation for predicting the hydraulic conductivity of unsaturated soils. Soil Sci. Soc. Am. J., 44: 892-898. http://www.h2ogeo.upc.es/Docencia/Flujo\%20y\%2 0Transporte\%20Multifase/Lectura_3.pdf

Zienkiewicz, O.C. and R.L. Taylor, 1989. The Finite Element Method. 4th Edn., McGraw-Hill, London, pp: 648. 